\title{
A microarray-based approach to evaluate the functional significance of protein-binding motifs
}

\author{
Michael D. Sinzinger ${ }^{1} \cdot$ Yi-Da Chung ${ }^{1} \cdot$ Merel J. W. Adjobo-Hermans ${ }^{1} \cdot$ Roland Brock $^{1}$
}

Received: 18 October 2015 /Revised: 14 January 2016 / Accepted: 1 February 2016 / Published online: 18 February 2016

(C) The Author(s) 2016. This article is published with open access at Springerlink.com

\begin{abstract}
Intracellular proteins comprise numerous peptide motifs that interact with protein-binding domains. However, using sequence information alone, the identification of functionally relevant interaction motifs remains a challenge. Here, we present a microarray-based approach for the evaluation of peptides as protein-binding motifs. To this end, peptides corresponding to protein interaction motifs were spotted as a microarray. First, peptides were titrated with a pan-specific binder and the apparent $K_{\mathrm{d}}$ value of this binder for each peptide was determined. For phosphotyrosine-containing peptides, an anti-phosphotyrosine antibody was employed. Then, in the presence of the pan-specific binder, arrays were competitively titrated with cell lysate and competition constants were determined. Using the Cheng-Prusoff equation, binding constants for the pan-specific binder and inhibition constants for the lysates were converted into affinity constants for the lysate. We experimentally validate this method using a phosphotyrosine-binding $\mathrm{SH} 2$ domain as a further reference. Furthermore, strong binders correlated with binding motifs engaging in numerous interactions as predicted by Scansite. This method provides a highly parallel and robust approach to identify peptides corresponding to interaction motifs with strong binding capacity for proteins in the cell lysate.
\end{abstract}

Electronic supplementary material The online version of this article (doi:10.1007/s00216-016-9382-6) contains supplementary material, which is available to authorized users.

Roland Brock

roland.brock@radboudumc.nl

1 Department of Biochemistry, Radboud Institute for Molecular Life Sciences, Radboud University Medical Center, Geert Grooteplein 28, 6525 GA Nijmegen, The Netherlands
Keywords Peptide microarray - Dissociation constant . EC50 - T cell signalling $\cdot$ Cheng-Prusoff equation $\cdot$ Protein interaction

\section{Introduction}

In the analysis of biomolecular interactions, microarray-based approaches have greatly expanded the information content that can be obtained in one single experiment. The interaction of one target molecule with numerous immobilised capture molecules can be probed in a highly parallel fashion. Besides DNA microarrays [1], microarrays are used to study protein interactions with antibodies [2], proteins [3] or peptides [4] as capture molecules immobilised on a functionalised surface. In addition to providing qualitative data on interaction preferences, microarrays can also be used for obtaining quantitative data on molecular interactions $[5,6]$.

In cellular signal transduction, a major part of proteinprotein interactions are realised by modular domains [7-9]. Interaction networks have been inferred by a compilation of binding patterns of probe molecules that were individually incubated on microarrays of capture molecules. In these studies, capture molecules comprised of all members of a given type of interaction domain and probe molecules were peptide motifs $[10,11]$.

However, to characterise the functional significance of an interaction motif in engaging in molecular interactions in comparison to related motifs, this compilation of binding profiles is inefficient. Instead, a method is needed that provides direct access to the affinity of interaction motifs towards the cellular proteome. As we have shown before, instead of using purified binders, crude cell lysates can also be used as a source of target proteins, enabling for example the detection of signalling-dependent changes in molecular interactions $[12$, 
13] and the effect of endogenous competitors on binding profiles [14].

In this study, we set out to further extend these concepts to provide information on the general affinity of interaction motifs immobilised on the microarrays towards the cellular proteome. Phosphotyrosine-containing peptides, interacting with SH2 domains, were selected to validate the approach. In a first step, microarrays were titrated with an $\alpha$-phosphotyrosine antibody serving as a pan-specific binder. In a second step, binding of the antibody was competed out by incubation with cell lysate. Using the apparent dissociation constants for the panspecific binder as derived from the binding isotherms $[15,16]$, $\mathrm{EC}_{50}$ values for the lysate were converted into binding constants for the proteome using the Cheng-Prusoff equation [17]. We further validated the approach for a protein domain as a reference binder, extending the applicability of the method to interactions for which a pan-specific antibody is not available. The prediction of functional significance showed a strong positive correlation with the number of interactors as predicted by Scansite [18]. In the functional characterisation of interaction motifs, this approach constitutes a highly valuable alternative to the compilation of binding patterns.

\section{Material and methods}

\section{Generation of peptide microarrays}

Peptides that correspond to known interaction motifs involved in the formation of protein complexes in T cell signalling were purchased from EMC microcollections (Tübingen, Germany). All peptides carried an extra cysteine residue and a free Nterminus for immobilisation on the microarray substrates and a C-terminal amidation (see Electronic Supplementary Material (ESM), Table S1).

For generation of microarrays, peptide stock solutions $(3 \mathrm{mM})$ in DMF were diluted 30 times with phosphate buffer $(100 \mathrm{mM}, \mathrm{pH}$ 8) supplemented with $0.006 \%(v / v)$ Triton X100. $\mathrm{N}$-Hydroxysuccinimide-preactivated slides served as substrates for immobilisation (Nexterion Slide H, Schott Nexterion/Peq-Lab, Erlangen, Germany) using a NanoPlotter NP2.0 (GeSIM, Großerkmannshof, Germany), which employs piezo-driven pipetting tips to dispense peptide solutions. Microarray slides comprised 16 subarrays of doublets of each peptide. For each peptide, a volume of $1.2 \mathrm{nl}$ was dispensed at a centre-to-centre spacing of $500 \mu \mathrm{m}$. During printing, temperature was maintained at $15{ }^{\circ} \mathrm{C}$ and air humidity at $65 \%$.

\section{Preparation of cell lysates}

Jurkat T cell leukaemia cells were maintained in RPMI 1640 medium (PAN-Biotech, Aisenbach, Germany) supplemented with $10 \%$ foetal calf serum at $37{ }^{\circ} \mathrm{C}$ in $5 \% \mathrm{CO}_{2}$. For the preparation of lysates, cells were resuspended in lysis buffer ( $1 \%$ Triton X-100, $50 \mathrm{mM} n$-octyl-D-glucopyranoside (Fluka, Taufkirchen, Germany), $20 \mathrm{mM}$ Tris, $1 \mathrm{mM}$ EDTA, $150 \mathrm{mM}$ $\mathrm{NaCl}, 1 \mathrm{mM} \mathrm{Na}_{3} \mathrm{VO}_{4}, \mathrm{pH} 7.5$, and complete protease inhibitor cocktail (Roche Applied Science, Mannheim, Germany)). Incubation on ice for $1 \mathrm{~h}$ was followed by centrifugation at $20,000 \times g$ at $4{ }^{\circ} \mathrm{C}$ for $15 \mathrm{~min}$ to remove cell debris. Transmembrane proteins were extracted from lipid rafts by using $N$-octyl-D-glucopyranoside. Protein concentrations were measured by Bradford Assay.

\section{Expression and purification of recombinant GRB2-SH2}

The PCR product of the SH2 domain of GRB2 (GRB2-SH2) was cloned into the $\mathrm{pET} 160 / \mathrm{GW} / \mathrm{D}-\mathrm{TOPO}$ vector (Invitrogen, Breda, The Netherlands), which contains a region encoding for a His-tag. The plasmid was used to perform a transformation into One Shot TOP10 competent cells (Invitrogen). Bacteria were lysed in CellLytic B buffer (Sigma-Aldrich, Steinheim, Germany) and 1 min of sonication was used to lyse the transformed bacteria. Pellets were created by spinning the lysates twice for $10 \mathrm{~min}$ at $20,000 \times g, 4{ }^{\circ} \mathrm{C}$. Protein purification from the protein-containing supernatant was performed with HIS-Select Cartridges H 8286 (Sigma-Aldrich, Steinheim, Germany). This step was followed by a dialysis against phosphate-buffered saline (PBS) with the addition of $1 \mathrm{mM}$ mercaptoethanol for 3 days at $4{ }^{\circ} \mathrm{C}$ while stirring in a dialysis cassette (Slide-A-Lyzer, Pierce, Rockford, USA). The purified protein solution was further concentrated by an Amicon Ultra- 15 and Ultracel $-5 \mathrm{k}$ centrifugation tube (Millipore, Schwalbach, Germany). The concentration of expressed protein was determined by photometric measurements at $\mathrm{OD}_{280}$. The concentration of GRB2-SH2 was determined in Western blots by quantitatively analysing obtained bands of purified GRB2-SH2 in an Odyssey Infrared Imaging System (Li-Cor Biosciences, Bad Homburg, Germany) in comparison with a bovine serum albumin (BSA) standard.

\section{Microarray experiments}

Sixteen incubation chambers with identical subarrays consisting of peptides derived from binding motifs of signalling proteins (see ESM Table S1) were generated by attaching a clip-on frame to the microarray substrate (ProPlate Multiarray System, Grace Biolabs, Molecular Probes, Eugene, OR, USA). The typical incubation volume for the subarrays was $50 \mu \mathrm{l}$. Microarrays were either incubated with an $\alpha$-pY antibody ( $\alpha$-pTyr 100, 9411, Cell Signalling, Frankfurt am Main, Germany) at the indicated concentrations or co-incubated with cell lysate at the indicated concentrations for $3 \mathrm{~h}$ at $4{ }^{\circ} \mathrm{C}$. Additionally, in another set of experiments, recombinant GRB2-SH2 was incubated on microarrays alone 
or co-incubated with cell lysate employing an $\alpha$-penta HIS antibody (34600, Qiagen, Hilden, Germany) for the detection of His-tagged GRB2-SH2.

After incubation, microarrays were washed three times with washing buffer (PBS, $0.05 \%(w / v)$ BSA, $0.05 \%(w / v)$ Tween-20). For the detection of signals, microarrays were incubated with a secondary $\alpha$-mouse antibody conjugated with Alexa633 (A-21050, Invitrogen) at a concentration of $1 \mu \mathrm{g} / \mathrm{ml}$ for $15 \mathrm{~min}$ at RT followed by a last washing step with washing buffer. Microarrays were dried with nitrogen and scanned using a ProScanArray (PerkinElmer Life Sciences, Waltham, Massachusetts), and the data were analysed using ArrayPro Analyzer software (Media Cybernetics, Silver Spring, USA) as described before [13, 14]. Final data represented the mean signal intensities corrected for the median of a ring-shaped local background surrounding the respective peptide spot. Titrations with $\alpha$-pY antibody and GRB2-SH2 were performed to calculate dissociation constants (see below).

\section{Quantitative analyses of molecular interactions}

The resulting titration curves were fitted with Origin (OriginLab Corporation, v.6.1057, Northampton, USA) using a binding isotherm for a bimolecular interaction (Eq. 1):

$F_{\mathrm{abs}}=\frac{F_{\max }[\text { prot }]}{K_{d}+[\text { prot }]}$

$F_{\text {abs }}$ represents the intensity of a microarray spot after background correction and [prot] the concentration of the titrated binder. $K_{\mathrm{d}}$ and $F_{\max }$ were obtained from the fits.

For determination of $\mathrm{EC}_{50}$ values for competition with cell lysate, curves were fitted according to

$y=y_{0}+A e^{-x / t}$

with $y_{0}$ as the signal intensity of the $\alpha-p Y$ antibody or the recombinant GRB2-SH2 domain without cell lysate, $A$ the amplitude, $x$ the protein concentration in lysate, and $t$ the decay constant. $\mathrm{EC}_{50}$ values were calculated with

$\mathrm{EC}_{50}=-\ln 0.5 t$

With knowledge of the $\mathrm{EC}_{50}$ values of the antibody or protein domain for the individual peptides, $K_{\mathrm{d}}$ values for the lysate proteins were derived using the Cheng-Prusoff equation [17]

$K_{\mathrm{d}, \text { lysate protein }}=\frac{\mathrm{EC}_{50}}{1+\frac{[\alpha-p Y]}{K_{\mathrm{d}, \alpha-p Y}}}$

This dissociation constant reflects the affinity of the entirety of all proteins in the lysate towards a binding motif on the microarrays.

\section{Results}

\section{Determination of $K_{\mathrm{d}}$ and $\mathrm{EC}_{\mathbf{5 0}}$ for an anti-phosphotyrosine antibody}

To obtain general information on the activity of a peptide motif as a binder for the total cellular proteome, a competitive approach was selected. We focused our analysis on peptides containing phosphotyrosine motifs (ESM Table S1) that bind to protein domains such as the $\mathrm{SH} 2$ domain. An antiphosphotyrosine-directed antibody was chosen as a panspecific binder that could be detected by indirect immunofluorescence. Binding of cellular proteins could then be detected by competition of antibody binding (Fig. 1).

To render this approach quantitative, first the affinities of the $\alpha$-pY antibody towards the phosphotyrosine motifs of the microarrays were determined. Microarrays were titrated in six independent experiments with the antibody at concentrations ranging from 0.06 to $6.66 \mathrm{nM}$, which showed a concentrationdependent binding to the array towards saturation. This was observed for all of the phosphotyrosine peptides. The titration curves were fitted with a binding isotherm for a bimolecular interaction (Eq. 1, Fig. 2a, Table 1). In general, a coefficient of determination $\left(R^{2}\right)$ of 0.8 was used as a cutoff in order to score a peptide as a binder. For all phosphotyrosine (pY)-containing peptides, titration curves with an overall average coefficient of determination $\left(R^{2}\right)$ of 0.85 and average $K_{\mathrm{d}}$ values for the single peptides ranging from 0.28 to $1.32 \mathrm{nM}$ could be obtained. Regarding the poly-proline motif (PP) containing peptides present on the microarray, only on the peptide GAB2-509 in five experiments, a titration curve with an $R^{2}>0.8$ could be generated.

Next, the ability of cellular proteins to compete for antibody binding was assessed (Fig. $2 \mathrm{~b}$ ). $\mathrm{EC}_{50}$ values for inhibition of $\alpha$-pY antibody binding were acquired by incubation of the $\alpha$-phosphotyrosine ( $\alpha-p Y)$ antibody in a fixed concentration $(0.66 \mathrm{nM})$ with lysates of Jurkat cells in concentrations of $18,54,126$ and $180 \mu \mathrm{M}$ of the total lysate protein (four independent experiments). The protein content in the cell lysates was determined by Bradford Assay and converted into a molar protein concentration assuming the molecular weight of BSA $\left(M_{\mathrm{BSA}}=66,382 \mathrm{~g} / \mathrm{mol}\right)$. This is certainly an arbitrary choice but gave us the possibility to place the titration curves in the context of molar affinities. A total loss of signal of the $\alpha-p Y$ antibody was obtained for only a fraction (e.g. LATpY191) of peptides, validating the strength of binding of the $\alpha-p Y$ to the $p Y$ motifs. All competition experiments were fitted using Eq. 2, and $\mathrm{EC}_{50}$ values were calculated according to Eq. 3. Average $\mathrm{EC}_{50}$ values ranged from 12.28 to $54.07 \mu \mathrm{M}$. Both for the titration and the competition experiments, raw data were averaged without normalisation (Fig. 2a, b) as maximum signal intensities between single microarrays were in the same range. 
Fig. 1 Titration and competition of $\alpha$-pY antibody binding to peptide microarrays. a Titration of $\alpha$ pY. Concentrations refer to the concentrations of the $\alpha$-pY antibody. Binding was detected by indirect immunofluorescence. $\mathbf{b}$ Competition of $\alpha-p Y$ binding through addition of increasing concentrations of cell lysate. The indicated 'concentrations' refer to the total concentration of protein in cell lysates determined by Bradford Assay. $\alpha-p Y$ was used in a fixed concentration of $0.33 \mathrm{nM}$

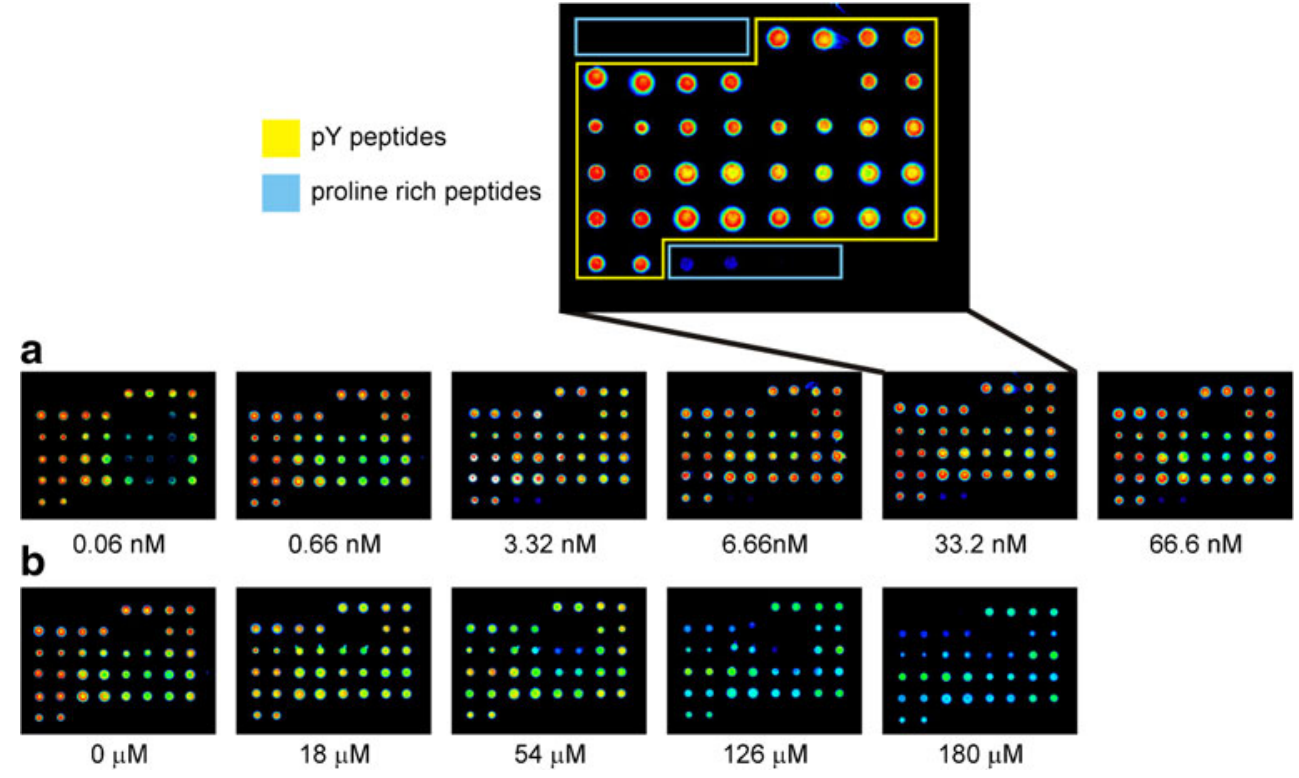

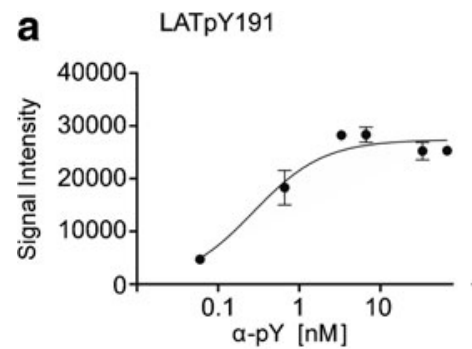

LATpY226

PLCYpY783

SigpY437

b
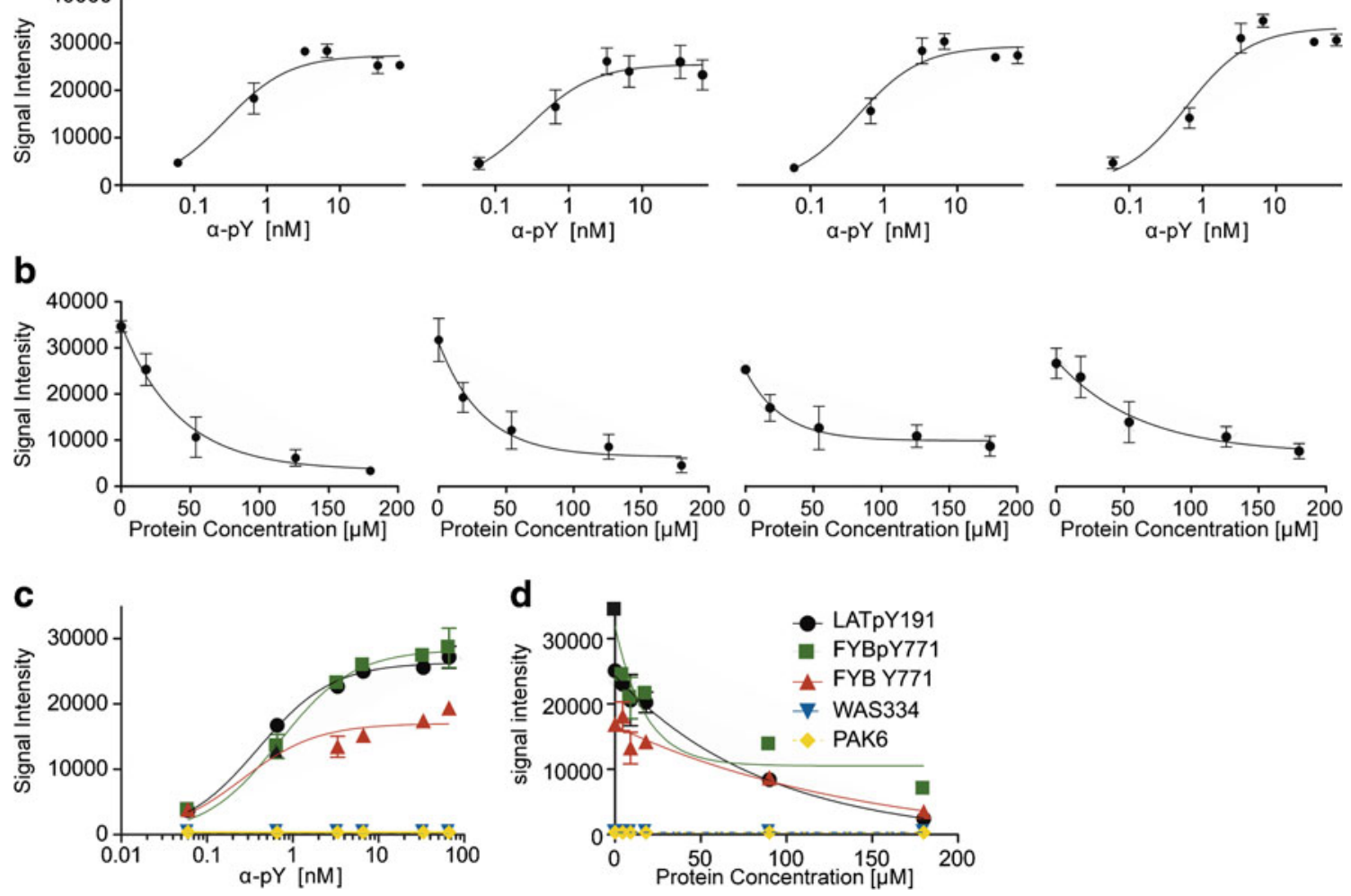

Fig. 2 Examples for binding curves for titration and competition of $\alpha$-pY antibodies on the peptide microarrays. a Titration curves on four different phosphotyrosine peptides LATpY191, LATpY226, PLC $\gamma p Y 783$ and SigpY437. Depicted are means and standard errors of six independent experiments. b Competitions were performed with a fixed concentration of $0.33 \mathrm{nM} \alpha-\mathrm{pY}$ and increasing concentrations of cell lysate which were converted into molar protein concentrations assuming an average molecular weight corresponding to the one of BSA. The displayed competition curves are for the peptides from the respective titration curve above (a) and represent means and standard errors of four independent experiments. c Control experiments for the specificity of

the $\alpha-p Y$ antibody on the microarrays. Titration curves for the $\alpha-p Y$ antibody on two phosphorylated peptides, one non-phosphorylated peptide and two proline-rich peptides are shown. $\mathbf{d}$ Control experiments for the specificity of binders in cell lysate. Cell lysates of Jurkat cells in different concentrations per subarray were co-incubated with the $\alpha$-pY antibodies to check for the ability of proteins in the lysate to compete with antibody binding. Results for two phosphorylated peptides, one nonphosphorylated peptide and two proline-rich peptides are depicted. c, d Show means of relative signal intensities and refer to two independent experiments; the error bars indicate standard errors 
Table 1 Dissociation constants and $\mathrm{EC}_{50}$ values for binding of proteins to phosphotyrosine peptides. $\mathrm{EC}_{50}$ values were determined by competition of $\alpha$ pY with cell lysate. Error ranges represent standard deviations. As $\mathrm{EC}_{50}$ values were calculated from averaged competition curves, standard deviations for $K_{\mathrm{d}}$ values of the approach using GRB2-SH2 are not available

\begin{tabular}{|c|c|c|c|c|}
\hline Peptide & $K_{\mathrm{d}} \alpha-\mathrm{pY}[\mathrm{nM}]$ & $\mathrm{EC}_{50}[\mu \mathrm{M}]$ & $\begin{array}{l}K_{\mathrm{d}} \text { lysate proteins } \\
(\alpha-\mathrm{pY})[\mu \mathrm{M}]\end{array}$ & $\begin{array}{l}K_{\mathrm{d}} \text { lysate proteins } \\
(\mathrm{GRB} 2-\mathrm{SH} 2)[\mu \mathrm{M}]\end{array}$ \\
\hline SigpY437 & $0.66 \pm 0.46$ & $44 \pm 40$ & $22 \pm 20$ & 0.1 \\
\hline LATpY132 & $0.41 \pm 0.38$ & $29 \pm 34$ & $11 \pm 13$ & 1.5 \\
\hline CD3乙pY72/83 & $0.69 \pm 0.61$ & $50 \pm 53$ & $25 \pm 27$ & 1.3 \\
\hline PLC $\gamma p Y 783$ & $0.55 \pm 0.33$ & $16 \pm 5$ & $7 \pm 2$ & 1.0 \\
\hline ZAPpY296 & $1.32 \pm 0.59$ & $43 \pm 45$ & $27 \pm 28$ & 3.3 \\
\hline ZAPpY319 & $0.60 \pm 0.46$ & $54 \pm 68$ & $26 \pm 32$ & 2.0 \\
\hline LATpY226 & $0.44 \pm 0.27$ & $37 \pm 27$ & $15 \pm 11$ & 2.2 \\
\hline LATpY191 & $0.35 \pm 0.28$ & $47 \pm 44$ & $16 \pm 15$ & 4.9 \\
\hline SHP1pY564 & $0.89 \pm 0.57$ & $30 \pm 17$ & $17 \pm 10$ & 4.4 \\
\hline FYBpY595 & $0.77 \pm 0.28$ & $41 \pm 31$ & $17 \pm 19$ & - \\
\hline FYBpY625 & $0.46 \pm 0.15$ & $50 \pm 26$ & $17 \pm 13$ & - \\
\hline FYBpY651 & $0.28 \pm 0.09$ & $54 \pm 28$ & $12 \pm 9$ & - \\
\hline FYBpY771 & $0.50 \pm 0.23$ & $12 \pm 3$ & $5 \pm 1$ & - \\
\hline
\end{tabular}

$-=$ not determined
In addition to the phosphotyrosine peptides, a set of proline-rich peptides (ESM Table S1) and, in an additional experimental series, one non-phosphorylated peptide (FYB Y771) were also included on the arrays and served as internal controls for the specificity of the competition for phosphotyrosine-containing motifs. The $\alpha-p Y$ antibody showed binding on the non-phosphorylated FYB Y771 peptide (see Fig. 2c); however, the maximum signal intensities on FYB Y771 were only half of the ones on FYBpY771 suggesting a high off-rate of the $\alpha$-pY antibody on this peptide. In direct comparison of the phosphorylated variant of the FYB peptide with the nonphosphorylated one, in competition experiments with cell lysate, a difference in the $\mathrm{EC}_{50}$ values of almost 1 order of magnitude could be observed $(12.24 \mu \mathrm{M}$ for FYBpY771 vs. $100.3 \mu \mathrm{M}$ for FYB Y771). This demonstrates that the phosphotyrosine-containing peptide probed specifically for binding of proteins from the cell lysate as the $\alpha-p Y$ antibody is competed off more efficiently on the pY peptide compared to the non-phosphorylated peptide. That a titration curve could be detected at all, we consider a coincidence resulting from the residual binding capacity of the antibody on this peptide.

For the two proline-rich peptides WAS334 and PAK6 depicted in Fig. 2c, no titration curves could be generated. This is in line with the signals shown in the magnification in Fig. 1a.

These results are further confirmed by earlier experiments, in which competition experiment were performed with peptides in solution corresponding to arrayed peptides and a concentration-dependent decrease of signal intensities for proteins binding to the arrayed peptides could be detected [13].

\section{Determination of the general affinity of cellular proteins towards $\mathrm{pY}$ motifs}

The competition experiments above provided information on the activity of a peptide as an $\mathrm{SH} 2$ domain-binding motif for the entire proteome that did not require any a priori knowledge on potential binders. However, strong competition could be a function of a relatively weaker binding of the $\alpha$-pY antibody, a strong binding of the lysate or both. In order to correct the $\mathrm{EC}_{50}$ values for the binding characteristics of the $\alpha-\mathrm{pY}$ antibody, the Cheng-Prusoff equation (Eq. 4) was applied for calculation of $K_{\mathrm{d}}$ values of the lysate proteins. Since for the binding of the antibody to the individual peptides the $K_{\mathrm{d}}$ values showed only little variation, there was a strong positive correlation of $\mathrm{EC}_{50}$ and $K_{\mathrm{d}}$ values (Fig. 3a).

Outliers of this correlation were SHP1pY564 and LATpY191. For SHP1pY564 and also for ZAPpY296, which were at the edge of the confidence interval, the $\alpha$-pY antibody showed a relatively low affinity leading to a low $\mathrm{EC}_{50}$ value in the competition experiments with cell lysate and thus to an overestimation of the affinity by potential binders in the lysate. This is why these data showed a shift towards the $x$-axis. LATpY191, on the contrary, displayed a high affinity for the $\alpha$-pY antibody (see also example in Fig. 2a), which caused an underestimation of the general affinity, reflected by a relatively high $\mathrm{EC}_{50}$. The conversion of $\mathrm{EC}_{50}$ values in $K_{\mathrm{d}}$ values accounts for differences in $\mathrm{EC}_{50}$ values resulting from different affinities of the antibody, thereby providing corrected information for the potential of the peptides for the binding to lysate proteins.

In addition, strong competition by the lysate could be a result of either high-affinity binding of individual proteins or of binding of several proteins. In order to address this question, the internet resource Scansite was used to predict the 

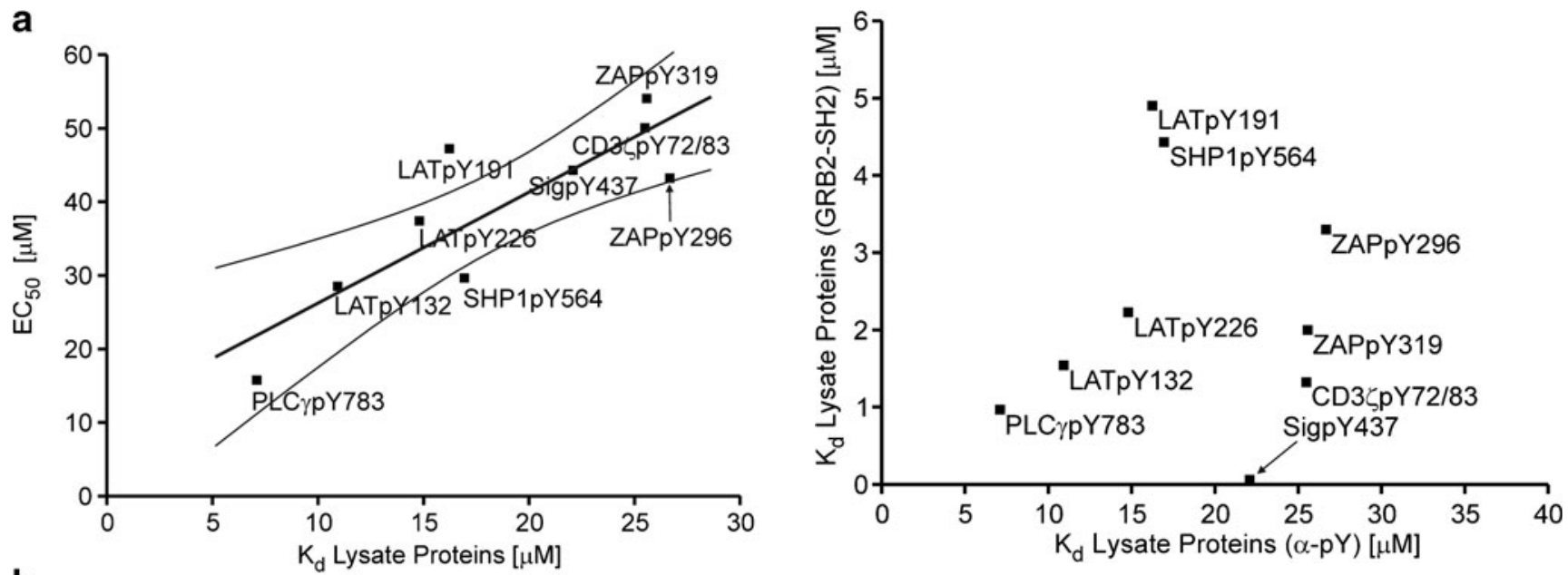

b

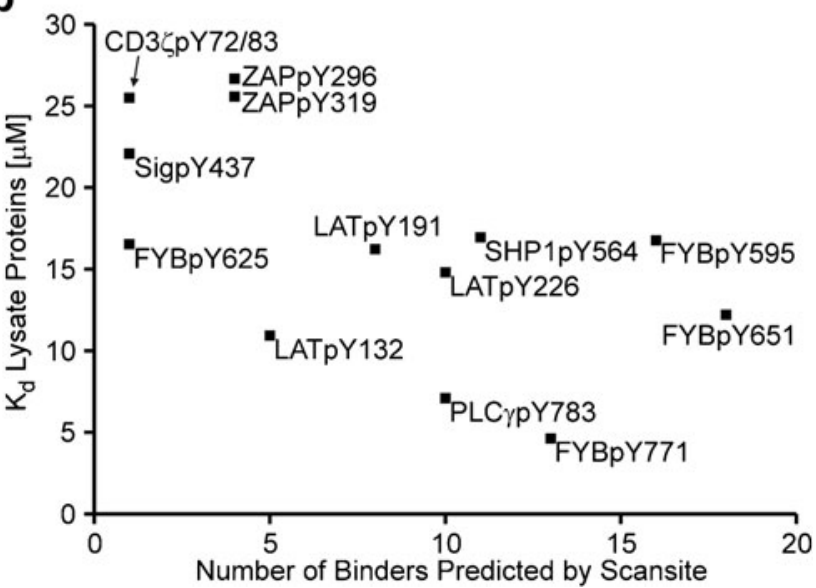

Fig. 4 Plot of dissociation constants of endogenous binders in cell lysate derived from experiments with GRB2-SH2 versus the $K_{\mathrm{d}}$ of the cellular proteome derived from experiments with $\alpha-p Y$ antibody. Data points represent mean values of six independent experiments

Remarkably, there was a clear correlation between the dissociation constants of the lysate proteins and the number of binders predicted by Scansite (Fig. 3b). A higher affinity for the cellular proteome correlated with a high number of predicted binders. This finding suggests that the collective affinity of a cellular proteome to a binding motif is, for a major part, rather determined by the number of binders than by the expression level and/or affinity of individual interactors.

The data on the FYB peptides was further validated by comparison to the recently published mass spectrometry results and functional analyses. In the microarray experiments, FYBpY771 showed the highest affinity of all four FYB peptides in line with data obtained by ${ }^{18} \mathrm{O}$ labelling that had demonstrated that this site had the largest number of binding partners [19]. Moreover, mutation of this residue for phenylalanine had the strongest impact on T cell activation [20].

number of potential interactors. Scansite is based on results from oriented peptide library and phage display experiments and finds short protein sequence motifs that interact with modular signalling domains [18].

The number of binders as predicted by Scansite was plotted against the $K_{\mathrm{d}}$ values of the lysate proteins. For this examination, we also included four peptides derived from the adaptor protein FYB/ADAP from another experimental series. For these peptides, binders had been identified using mass spectrometry-based approaches [19] and the functional significance of individual phosphotyrosine residues had been addressed using a knock-in approach [20]. FYB/ADAP couples TCR stimulation to the activation of integrins by mediating increased integrin avidity [21]. Like other adaptor proteins, FYB/ADAP is phosphorylated on multiple sites and as a consequence involved in complex formation with several proteins [22]. In our competition experiments, all FYB-derived peptides had shown binding to the cellular proteome (see ESM, Fig. S1).

\section{Use of protein domains as pan-specific binders}

For many peptide motifs, a pan-specific binder such as the $\alpha$-pY antibody will not be available. In such cases, a protein domain with a broad-band binding specificity may serve as a surrogate. In order to explore this option for the phosphotyrosinecontaining motifs, we conducted analogous competition experiments with the recombinant $\mathrm{SH} 2$ domain of the adaptor protein GRB2 [23, 24]. Again, we took advantage of the Cheng-Prusoff equation, using $\mathrm{EC}_{50}$ values obtained for titrations of GRB2$\mathrm{SH} 2$ binding with cell lysate and $K_{\mathrm{d}}$ values of the recombinant GRB2-SH2 protein domain that were described in our recently published manuscript [14].

In analogy to the $\alpha$-phosphotyrosine antibody, the titration of the recombinant GRB2-SH2 domain with cell lysates provides an approach for obtaining general information on the activity of peptide motifs as binders for the total cellular 
proteome. However, the GRB2-SH2 domain by itself possesses a clear preference for certain motifs, which may impose a restriction for the use of a protein domain as a reference binder. In order to assess the relevance of this restriction, we compared the $K_{\mathrm{d}}$ derived from the competition experiments with GRB2-SH2 and cell lysate with the $K_{\mathrm{d}}$ obtained from the experiments with the $\alpha-p Y$ and cell lysate (Fig. 4).

The plot of these $K_{\mathrm{d}}$ values showed a good correlation for the motifs PLC $\gamma p Y 783$, LATpY132, LATpY226 and ZAPpY296 for which GRB2 is a good binder. In contrast, the data points for LATpY191 and SHP1pY564, and SigpY437, ZAPpY319 and CD $\zeta p Y 72 / 83$ were above or below the linear correlation defined by the first four peptides. The LATpY191 motif has a strong affinity for the SH2 domain of GRB2 $[25,26]$ leading to a rather small competition on this motif by other binders in the cell lysate. The same holds true for SHP1pY564 [27]. SigpY437, in contrast, is a poor binder for which already low concentrations of lysate show full competition.

\section{Discussion}

Here, we present a competition-based microarray-approach to provide information on the significance of interaction motifs for the cellular proteome. The analyses benefited from a consequent adaptation of biochemical protocols to the microarray format. Titrations yielded binding isotherms for a recombinant protein and an antibody. By application of the Cheng-Prusoff equation to competitive titrations with crude cell lysates, these could then be translated into $K_{\mathrm{d}}$ values of the total proteome for the peptides on the microarrays. Importantly, the resulting predictions of binding capacity correlated well with Scansite predictions and, for the FYB/ADAP peptides, with standard proteomics and functional data. These results underscore and extend the potential of peptide microarrays in parallel biochemical approaches $[13,16]$.

Nevertheless, the absolute binding constants obtained in the various experiments also give clear indications that the microarray experiments are operating far from equilibrium. Binding constants for the cellular proteome using the GRB2SH2 domain as a competitor were up to 20 times smaller than those obtained with the anti-phosphotyrosine antibody as a competitor. While with the GRB2 domain-binding constants were lower than typically expected for $\mathrm{SH} 2$ domains, for the antibody, they were higher. Previously, a strong agreement between microarray-derived and SPR-derived $K_{\mathrm{d}}$ values was observed if microarrays were directly titrated with fluorescently labelled peptides instead of protein domains followed by indirect immunofluorescence $[10,11,16]$. Indirect immunofluorescence labelling requires several wash steps and periods of incubation. To prevent dissociation of bound proteins, wash steps and incubations with antibodies were conducted as short as possible. Owing to the non-equilibrium binding kinetics and dissociation introduced by any one of these steps, the exact nature of the observed differences for the approach with GRB2-SH2 and the anti-phosphotyrosine antibody observed in our case remains unknown. It has to be noted that mass transport limitation effects on our microarrays cannot be ruled out. When using high affinity, high molecular weight binders, binding kinetics can rapidly become diffusion limited $[6,28$, 29]. Thus, in this respect, we consider perfusion-based biosensing systems as powerful as our microarray-based approach. However, very clearly, the microarray operates at much lower sample consumption. Making larger amounts of cell lysates would be a limiting factor for a biosensing system.

For the GRB2-SH2 domain, the results demonstrate the general feasibility of the use of protein domains as reference ligands for the profiling of interaction motifs. However, the Cheng-Prusoff equation did not correct for major differences in the binding affinity of the reference binder, which may most likely also be attributed to the lack of equilibrium conditions. Therefore, the data has to be critically evaluated against the affinity of the pan-specific binder for the interaction motif.

In summary, the results presented in this research demonstrate the capacity of peptide microarrays to provide information on the significance of individual peptide motifs as protein binders for the total proteome. In contrast to previous approaches, this protocol does not require fluorescent labelling of the proteome [30-32]. Instead, detection of the reference binder is required. Even though there is no discrimination between an individual peptide binding a certain protein with very high affinity or several proteins with intermediate affinity, our comparison with the number of predicted binders by Scansite suggests that a strong interaction of the lysate for the binding motifs examined here is a result of many interactors. This information is highly valuable for a general assessment of the significance of a peptide/protein domain as an interaction motif.

Acknowledgments R. B. acknowledges financial support by the Volkswagen Foundation ("Nachwuchsgruppen an Universitäten," I/77 472).

\section{Compliance with ethical standards}

Conflict of interest The authors declare that they have no competing interests.

Open Access This article is distributed under the terms of the Creative Commons Attribution 4.0 International License (http:// creativecommons.org/licenses/by/4.0/), which permits unrestricted use, distribution, and reproduction in any medium, provided you give appropriate credit to the original author(s) and the source, provide a link to the Creative Commons license, and indicate if changes were made. 


\section{References}

1. Ramsay G. DNA chips: state-of-the art. Nat Biotechnol. 1998;16(1):40-4. doi:10.1038/nbt0198-40.

2. Angenendt P, Glökler J, Sobek J, Lehrach H, Cahill DJ. Next generation of protein microarray support materials: evaluation for protein and antibody microarray applications. J Chromatogr A. 2003;1009(1-2):97-104.

3. Zhu H, Bilgin M, Bangham R, Hall D, Casamayor A, Bertone P, et al. Global analysis of protein activities using proteome chips. Science. 2001;293(5537):2101-5. doi:10.1126/science.1062191.

4. Salisbury CM, Maly DJ, Ellman JA. Peptide microarrays for the determination of protease substrate specificity. J Am Chem Soc. 2002;124(50):14868-70.

5. André T, Reichel A, Wiesmüller KH, Tampé R, Piehler J, Brock R. Selectivity of competitive multivalent interactions at interfaces. Chem Eur J Chem Biol. 2009;10(11):1878-87.

6. Elbs M, Brock R. Determination of binding constants on microarrays with confocal fluorescence detection. Anal Chem. 2003;75(18):4793-800.

7. Clements JL, Boerth NJ, Lee JR, Koretzky GA. Integration of T cell receptor-dependent signaling pathways by adapter proteins. Annu Rev Immunol. 1999;17:89-108. doi:10.1146/annurev.immunol.17. 1.89 .

8. Myung PS, Boerthe NJ, Koretzky GA. Adapter proteins in lymphocyte antigen-receptor signaling. Curr Opin Immunol. 2000;12(3): 256-66.

9. Pawson T, Nash P. Assembly of cell regulatory systems through protein interaction domains. Science. 2003;300(5618):445-52. doi:10.1126/science.1083653.

10. Stiffler MA, Chen JR, Grantcharova VP, Lei Y, Fuchs D, Allen JE, et al. PDZ domain binding selectivity is optimized across the mouse proteome. Science. 2007;317(5836):364-9. doi:10.1126/science. 1144592.

11. Stiffler MA, Grantcharova VP, Sevecka M, MacBeath G. Uncovering quantitative protein interaction networks for mouse PDZ domains using protein microarrays. J Am Chem Soc. 2006;128(17):5913-22. doi:10.1021/ja060943h.

12. Stoevesandt O, Elbs M, Köhler K, Lellouch AC, Fischer R, André $\mathrm{T}$, et al. Peptide microarrays for the detection of molecular interactions in cellular signal transduction. Proteomics. 2005;5(8):2010-7. doi:10.1002/pmic.200401095.

13. Stoevesandt O, Köhler K, Wolf S, André T, Hummel W, Brock R. A network analysis of changes in molecular interactions in cellular signaling. Mol Cell Proteomics. 2007;6(3):503-13. doi:10.1074/ mcp.M600383-MCP200.

14. Sinzinger MD, Ruttekolk IR, Gloerich J, Wessels H, Chung Y-D, Adjobo-Hermans MJW, et al. Peptide microarrays to probe for competition for binding sites in a protein interaction network. $\mathrm{J}$ Proteome. 2013;89:71-80. doi:10.1016/j.jprot.2013.05.031.

15. Tapia V, Bongartz J, Schutkowski M, Bruni N, Weiser A, Ay B, et al. Affinity profiling using the peptide microarray technology: a case study. Anal Biochem. 2007;363(1):108-18. doi:10.1016/j.ab. 2006.12.043.

16. Jones RB, Gordus A, Krall JA, MacBeath G. A quantitative protein interaction network for the ErbB receptors using protein microarrays. Nature. 2006;439(7073):168-74. doi:10.1038/nature04177.

17. Cheng Y, Prusoff WH. Relationship between the inhibition constant (K1) and the concentration of inhibitor which causes 50 per cent inhibition (I50) of an enzymatic reaction. Biochem Pharmacol. 1973;22(23):3099-108.
18. Obenauer JC, Cantley LC, Yaffe MB. Scansite 2.0: proteome-wide prediction of cell signaling interactions using short sequence motifs. Nucleic Acids Res. 2003;31(13):3635-41.

19. Lange S, Sylvester M, Schümann M, Freund C, Krause E. Identification of phosphorylation-dependent interaction partners of the adapter protein ADAP using quantitative mass spectrometry: SILAC vs (18)O-labeling. J Proteome Res. 2010;9(8):4113-22. doi:10.1021/pr1003054.

20. Sylvester M, Kliche S, Lange S, Geithner S, Klemm C, Schlosser A, et al. Adhesion and degranulation promoting adapter protein (ADAP) is a central hub for phosphotyrosine-mediated interactions in T cells. PLoS ONE. 2010;5(7), e11708. doi:10.1371/journal. pone. 0011708 .

21. Griffiths EK, Penninger JM. Communication between the TCR and integrins: role of the molecular adapter ADAP/Fyb/Slap. Curr Opin Immunol. 2002;14(3):317-22.

22. Lupher ML, Songyang Z, Shoelson SE, Cantley LC, Band H. The Cbl phosphotyrosine-binding domain selects a D(N/D)XpY motif and binds to the Tyr292 negative regulatory phosphorylation site of ZAP-70. J Biol Chem. 1997;272(52):33140-4.

23. Houtman JCD, Higashimoto Y, Dimasi N, Cho S, Yamaguchi H, Bowden B, et al. Binding specificity of multiprotein signaling complexes is determined by both cooperative interactions and affinity preferences. Biochemistry. 2004;43(14):4170-8. doi:10.1021/ bi0357311.

24. Houtman JCD, Yamaguchi H, Barda-Saad M, Braiman A, Bowden B, Appella E, et al. Oligomerization of signaling complexes by the multipoint binding of GRB2 to both LAT and SOS1. Nat Struct Mol Biol. 2006;13(9):798-805. doi:10.1038/nsmb1133.

25. Paz PE, Wang S, Clarke H, Lu X, Stokoe D, Abo A. Mapping the Zap-70 phosphorylation sites on LAT (linker for activation of $\mathrm{T}$ cells) required for recruitment and activation of signalling proteins in T cells. Biochem J. 2001;356(Pt 2):461-71.

26. Zhu M, Janssen E, Zhang W. Minimal requirement of tyrosine residues of linker for activation of $\mathrm{T}$ cells in TCR signaling and thymocyte development. J Immunol. 2003;170(1):325-33.

27. Minoo P, Zadeh MM, Rottapel R, Lebrun J-J, Ali S. A novel SHP1/Grb2-dependent mechanism of negative regulation of cytokinereceptor signaling: contribution of SHP-1 C-terminal tyrosines in cytokine signaling. Blood. 2004;103(4):1398-407. doi:10.1182/ blood-2003-07-2617.

28. Toegl A, Kirchner R, Gauer C, Wixforth A. Enhancing results of microarray hybridizations through microagitation. J Biomol Tech. 2003;14(3):197-204.

29. Model MA, Omann GM. Ligand-receptor interaction rates in the presence of convective mass transport. Biophys J. 1995;69(5): 1712-20. doi:10.1016/S0006-3495(95)80041-X.

30. Vinkenborg JL, Mayer G, Famulok M. Aptamer-based affinity labeling of proteins. Angew Chem Int Ed Engl. 2012;51(36):917680. doi:10.1002/anie.201204174.

31. Smolka MB, Zhou H, Purkayastha S, Aebersold R. Optimization of the isotope-coded affinity tag-labeling procedure for quantitative proteome analysis. Anal Biochem. 2001;297(1):25-31. doi:10. 1006/abio.2001.5318.

32. Cahill MA, Wozny W, Schwall G, Schroer K, Hölzer K, Poznanovic S, et al. Analysis of relative isotopologue abundances for quantitative profiling of complex protein mixtures labelled with the acrylamide/D3-acrylamide alkylation tag system. Rapid Commun Mass Spectrom. 2003;17(12):1283-90. doi:10.1002/ rcm.1046. 